\title{
Hemodynamic Determinants of Exercise-Induced ST-Segment Depression in Children with Valvar Aortic Stenosis
}

\author{
DANIEL A. KVESELIS, MD, ALBERT P. ROCCHINI, MD, AMNON ROSENTHAL, MD, \\ DENNIS C. CROWLEY, MD, MaCDONALD DICK, MD, A. REBECCA SNIDER, MD, \\ and CATHERINE MOOREHEAD
}

To evaluate the hemodynamic factors associated with treadmill-induced ST-segment depression in children with valvar aortic stenosis, 12 patients (mean age 13 years) with ST-segment depression during treadmill exercise and 5 patients (mean age 13 years) without ST-segment depression during treadmill exercise underwent exercise testing during cardiac catheterization. The left ventricular (LV) systolic pressure and LV outflow tract gradient at rest ( $177 \pm 25$ vs $138 \pm 8 \mathrm{~mm} \mathrm{Hg}$ and $59 \pm 18$ vs 23 $\pm 7 \mathrm{~mm} \mathrm{Hg}$, respectively) and corresponding pressures during maximal supine exercise (248 \pm 37 vs $189 \pm 17 \mathrm{~mm} \mathrm{Hg}$ and $112 \pm 34$ vs $52 \pm 14 \mathrm{~mm}$ $\mathrm{Hg})$ were significantly greater $(\mathrm{p}<0.01)$ in the pa- tients with exercise-induced ST-segment depression, although overlap existed. The $\mathrm{LV}-\mathrm{O}_{2}$ supplydemand ratio during maximal supine exercise was significantly less $(6.4 \pm 2.7$ vs $11.8 \pm 0.7 ; p<0.005)$ in patients with than in those without exercise-induced ST-segment depression. In fact, an $\mathrm{LV}-\mathrm{O}_{2}$ supply-demand ratio less than 11.0 was $100 \%$ sensitive and specific in predicting treadmill-induced ST-segment depression. These results suggest that although the development of ST-segment depression during treadmill exercise is related to LV systolic pressure and LV outflow gradient, its major hemodynamic determinant is the $\mathrm{LV}-\mathrm{O}_{2}$ supply-demand ratio.
The noninvasive evaluation of patients with valvar aortic stenosis (AS) frequently includes exercise treadmill testing. ${ }^{1}$ Correlation of the severity of the left ventricular (LV) outflow tract gradient has been made with the systolic blood pressure response, ${ }^{2-4}$ the decrease in R-wave amplitude ${ }^{5}$ and with significant $(0.10$ $\mathrm{mV}$ or more) $\mathrm{ST}$-segment depression during maximal exercise. ${ }^{6,7}$ Although the cause of ST-segment depression during maximal exercise is unknown, it has been hypothesized to be the result of subendocardial ischemia. ${ }^{6-8}$ Because direct measures of subendocardial blood flow are difficult to make in humans, the $\mathrm{LV}-\mathrm{O}_{2}$ supply-demand ratio has been used to estimate the adequacy of LV subendocardial blood flow. ${ }^{9-11}$ Several

From the Department of Pediatrics and Communicable Diseases, Section of Pediatric Cardiology, C.S. Mott Children's Hospital, The University of Michigan Medical School, Ann Arbor, Michigan. Manuscript received October 17, 1984; revised manuscript received December 26, 1984, accepted December 31, 1984.

Address for reprints: Albert P. Rocchini, MD, Section of Pediatric Cardiology, Department of Pediatrics, F1123 Box 66, C.S. Mott Children's Hospital, Ann Arbor, Michigan 48109. investigations have shown that patients with AS and ST-scgment depression at rest on the electrocardiogram have an altered $\mathrm{LV}-\mathrm{O}_{2}$ supply-demand ratio. ${ }^{12-16} \mathrm{This}$ study further evaluates the hemodynamic determinants of treadmill exercise-induced ST-segment depression in children with $\mathrm{AS}$ with special reference to the $\mathrm{LV}-\mathrm{O}_{2}$ supply-demand ratio at rest and during maximal exercise.

\section{Methods}

From January 1980 to July 1983, 17 children with AS and no ST-segment depression on a 12-lead surface clcctrocardiogram at rest underwent cardiac catheterization at the Univesity of Michigan's C.S. Mott Children's Hospital Cardiac Study Unit. Treadmill exercise (Bruce protocol) was performed 24 hours before cardiac catheterization. Electrocardiographic leads II, aVF and $V_{5}$ were continuously monitored and blood pressure was monitored using an automatic external cuff system (Critikon model 1165) at all stages of exercise and during recovery.

The patients were classified into 2 groups according to their response during treadmill exercise. One group consisted of 12 children, aged 8 to 17 years (mean 13), who had significant 
( $0.10 \mathrm{mV}$ or more) ST-segment depression during maximal treadmill exercise. Of these 12 patients, 5 (patients $1,3,7,10$ and 12) had undergone previous aortic valvotomy. The second group consisted of 5 children, aged 9 to 17 years (mean 13), with no ST-segment depression during maximal treadmill exercise. Patient 13 had undergone previous aortic valvotomy ('Table I). No patient had significant aortic regurgitation or symptoms.

Hemodynamic studies: Cardiac catheterization was performed in all patients in the supine position after premedication with morphine sulfate intramuscularly $(0.1 \mathrm{mg} / \mathrm{kg}$, maximum $5.0 \mathrm{mg}$ ) and diphenhydramine orally $(1 \mathrm{mg} / \mathrm{kg}$, maximum $50 \mathrm{mg}$ ). Using the percutaneous technique, 3 catheters were placed for pressure monitoring. In all patients, a thermodilution catheter was positioned in a branch pulmonary artery and a pigtail catheter was positioned in the ascending aorta. In 12 patients, a second pigtail catheter was inserted through the left femoral artery and positioned in the left ventricle, whereas in 5 patients the transseptal approach was used to monitor LV pressure. All patients were given heparin (100 units/kg body weight, maximum 2,000 units). Hemodynamic measurements of the right and left side of the heart at rest included simultaneous pulmonary artery, LV and aortic pressures using Statham pressure transducers and recorded on an Electronics for Medicine optical recorder at paper speeds of 50 or $100 \mathrm{~mm} / \mathrm{s}$; pulmonary blood flow (using an IL thermodilution catheter and an IL cardiac output computer); hemoglobin concentration; calculation of arterial $\mathrm{O}_{2}$ content (1.36 $\times$ hemoglobin $\times$ arterial $\mathrm{O}_{2}$ saturation); calculation of aortic valve area using the formula of Gorlin and Gorlin; and calculation of $\mathrm{LV}-\mathrm{O}_{2}$ supply-demand ratio. ${ }^{11}$

Exercise protocol: All patients underwent supine bicycle ergometry exercise until exhaustion with simultaneous measurement of pulmonary artery, $\mathrm{LV}$ and aortic pressures. The exercise protocol consisted of 4-minute stages with an initial workload of $200 \mathrm{kpm} / \mathrm{min}$ and increasing by $200-\mathrm{kpm} / \mathrm{min}$ increments until exhaustion. ${ }^{17}$ Hemodynamic measurements wer made between the third and fourth minute at each stage consisting of heart rate, pulmonary artery, LV and aortic pressures, cardiac index, pulmonary artery saturation and calculation of $\mathrm{LV}-\mathrm{O}_{2}$ supply-demand ratio.

$\mathrm{LV}-\mathrm{O}_{2}$ supply-demand ratio: The $\mathrm{LV}-\mathrm{O}_{2}$ supply-demand ratio has been demonstrated to estimate the adequacy of $\mathrm{LV}$ subendocardial blood flow when the blood vessels are maximally dilated. ${ }^{18}$ It is the ratio of the diastolic and systolic pressure time indexes multiplied by the arterial $\mathrm{O}_{2}$ content. The diastolic pressure time index is an estimate of coronary blood flow to the LV myocardium and is calculated by integrating the area between the aortic pressure curve and LV pressure curve from aortic valve closure to aortic valve opening. The systolic pressure time index is an estimate of the oxygen demand of the LV myocardium and is calculated by integrating the area beneath the $L V$ pressure curve during $L V$ ejection (Fig. 1). ${ }^{9}$

Statistical analysis: Statistical analysis was performed using the 2-tailed nonpaired Student $t$ test and the Bonferroni correction for multiple $t$ tests. Stepwise regression analysis of the data was performed to determine the most highly correlated variable to the development of ST-segment depression, as well as to the $\mathrm{LV}-\mathrm{O}_{2}$ supply-demand ratio. Results are given as mean \pm standard deviation.

\section{Results}

Treadmill exercise test: No significant differences were present between patients with or without STsegment depression with respect to endurance, heart rate at rest or during maximal exercise or change in systolic blood pressure during treadmill exercise (Table I).
REST

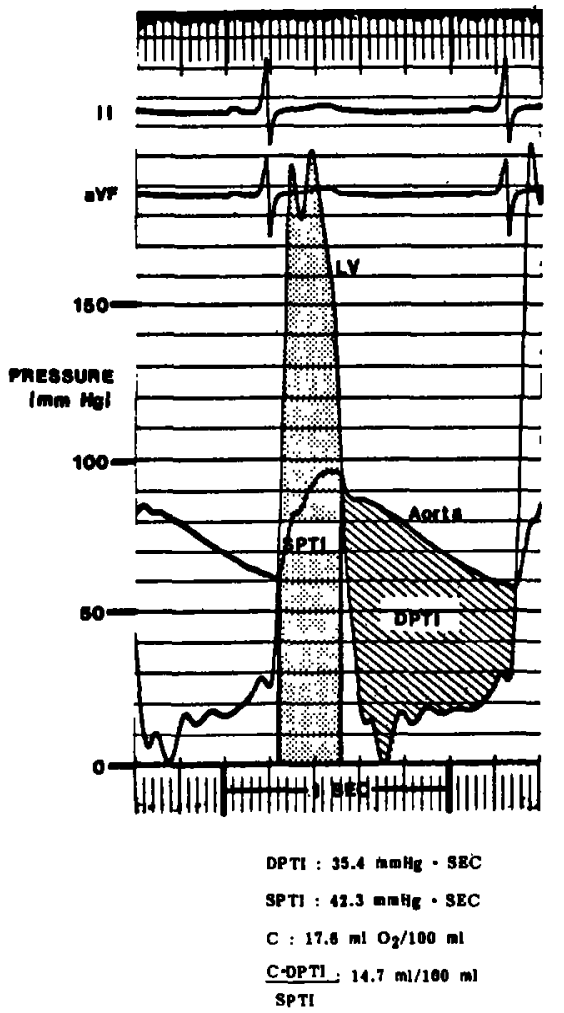

MAXIMUM EXERCISE

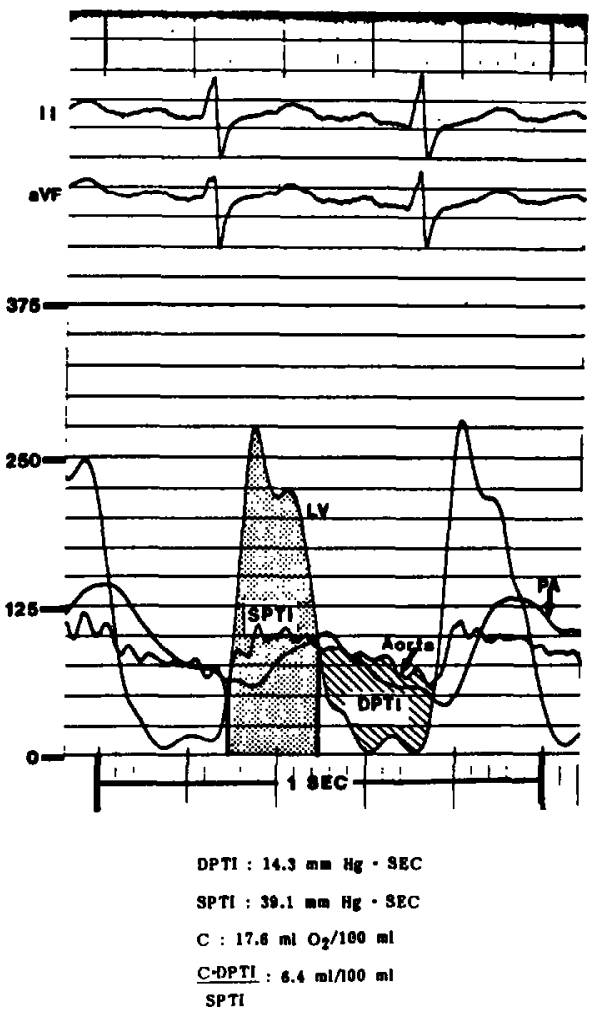

FIGURE 1. Left ventricular- $\mathrm{O}_{2}$ supplydemand ratio at rest and during maximal exercise. Note pressure scale change from rest to maximal exercise. $\mathrm{C}=$ arterial $\mathrm{O}_{2}$ content; C.DPTI/SPTI $=\mathrm{LV}-\mathrm{O}_{2}$ supplydemand ratio; DPTI = diastolic pressure time index: $L V=$ left ventricle; $P A=$ pulmonary artery; $\mathrm{SPTI}=$ systolic pressure time index. 
TABLE I Patient Data and Treadmill Exercise Test Results

\begin{tabular}{|c|c|c|c|c|c|c|}
\hline \multirow[b]{2}{*}{$\mathbf{P t}$} & \multirow{2}{*}{$\begin{array}{c}\text { Age } \\
(y r)\end{array}$} & \multirow{2}{*}{$\begin{array}{l}\text { Body Surface Area } \\
\qquad\left(\mathrm{m}^{2}\right)\end{array}$} & \multirow{2}{*}{$\begin{array}{l}\text { Duration } \\
\text { (min) }\end{array}$} & \multicolumn{2}{|c|}{$\begin{array}{l}\text { Heart Rate } \\
\text { (beats/min) }\end{array}$} & \multirow{2}{*}{$\begin{array}{c}\text { Change in Systolic } \\
\text { Blood Pressure } \\
\text { (mm Hg) }\end{array}$} \\
\hline & & & & Rest & Exercise & \\
\hline \multicolumn{7}{|c|}{ ST-Segment Depression } \\
\hline $\begin{array}{r}1 \\
2 \\
3 \\
4 \\
5 \\
6 \\
7 \\
8 \\
9 \\
10 \\
11 \\
12 \\
\text { Mean } \\
\pm \mathrm{SD}\end{array}$ & $\begin{array}{c}12 \\
10 \\
16 \\
16 \\
14 \\
10 \\
8 \\
11 \\
8.3 \\
16 \\
14 \\
15 \\
12.6 \pm 3.0\end{array}$ & $\begin{array}{c}1.39 \\
1.05 \\
1.70 \\
1.95 \\
1.53 \\
1.20 \\
0.96 \\
1.00 \\
0.96 \\
2.08 \\
1.90 \\
1.94 \\
1.47 \pm 0.43\end{array}$ & $\begin{array}{r}10 \\
13 \\
17 \\
17 \\
17 \\
15 \\
11 \\
13 \\
14 \\
12 \\
15 \\
17 \\
14 \pm 2.3\end{array}$ & $\begin{array}{c}70 \\
88 \\
78 \\
60 \\
80 \\
75 \\
70 \\
86 \\
92 \\
82 \\
84 \\
54 \\
77 \pm 11\end{array}$ & $\begin{array}{c}168 \\
205 \\
191 \\
185 \\
189 \\
155 \\
148 \\
172 \\
202 \\
180 \\
184 \\
180 \\
180 \pm 17\end{array}$ & $\begin{array}{c}-8 \\
+19 \\
+25 \\
+20 \\
+30 \\
-5 \\
+36 \\
0 \\
+40 \\
+25 \\
+45 \\
+42 \\
22 \pm 18\end{array}$ \\
\hline \multicolumn{7}{|c|}{ No ST-Segment Depression } \\
\hline $\begin{array}{r}13 \\
14 \\
15 \\
16 \\
17 \\
\text { Mean } \\
\pm S D\end{array}$ & $\begin{array}{r}17 \\
14 \\
9 \\
11 \\
15 \\
13.2 \pm 3.2\end{array}$ & $\begin{array}{c}1.63 \\
1.54 \\
0.96 \\
1.28 \\
1.50 \\
1.38 \pm 0.27\end{array}$ & $\begin{array}{c}16 \\
10 \\
14 \\
11 \\
18 \\
13.8 \pm 3.4\end{array}$ & $\begin{array}{c}83 \\
82 \\
85 \\
91 \\
72 \\
83 \pm 7\end{array}$ & $\begin{array}{c}188 \\
188 \\
164 \\
195 \\
205 \\
188 \pm 15\end{array}$ & $\begin{array}{r}+6 \\
+15 \\
+17 \\
+20 \\
+30 \\
18 \pm 9\end{array}$ \\
\hline
\end{tabular}

$\mathrm{SD}=$ standard deviation.

Hemodynamics: The hemodynamic data at rest and during maximal supine bicycle ergometry exercise are summarized in Table II. The LV systolic pressure at rest $(177 \pm 25$ vs $138 \pm 8 \mathrm{~mm} \mathrm{Hg}$ ) and during maximal supine bicycle exercise $(248 \pm 37$ vs $189 \pm 17 \mathrm{~mm} \mathrm{Hg})$ were significantly greater $(p<0.01)$ in patients with treadmill-induced ST-segment depression. The LV outflow tract gradient at rest $(59 \pm 18 \mathrm{~mm} \mathrm{Hg}$ vs $23 \pm 7 \mathrm{~mm} \mathrm{Hg}$ ) and during maximal supine bicycle exercise (112 \pm 34 $\mathrm{mm} \mathrm{Hg}$ vs $52 \pm 14 \mathrm{~mm} \mathrm{Hg}$ ) were also significantly greater $(p<0.01)$ in patients with treadmill-induced ST-segment depression (Fig. 2).

$\mathrm{LV}$ end-diastolic pressure at rest was similar between the 2 groups, whereas LV end-diastolic pressure during maximal supine bicycle exercise $(25 \pm 8 \mathrm{~mm} \mathrm{Hg}$ vs 13 $\pm 3 \mathrm{~mm} \mathrm{Hg}$ ) was significantly greater $(\mathrm{p}<0.05)$ in patients with treadmill-induced ST-segment depression (Table II, Fig. 2). In fact, the LV end-diastolic pressure increased more than $2 \mathrm{~mm} \mathrm{Hg}$ from rest to maximal exercise in 11 of 12 patients $(92 \%)$ with treadmill-induced ST-segment depression, whereas it did not increase in any patient without treadmill-induced STsegment depression. ${ }^{19}$

The aortic valve area indexed to body surface area was significantly less in those patients in whom STsegment depression developed at maximal treadmill exercise $\left(0.60 \pm 0.16 \mathrm{~cm}^{2} / \mathrm{m}^{2}\right.$ vs $0.80 \pm 0.15 \mathrm{~cm}^{2} / \mathrm{m}^{2}$, p $<0.05)$, though overlap existed.

The $\mathrm{LV}-\mathrm{O}_{2}$ supply-demand ratio during maximal supine bicycle exercise $(6.4 \pm 2.7$ vs $11.8 \pm 0.7, p<0.005)$ was significantly less in patients with treadmill-induced ST-segment depression (Fig. 3). No overlap existed between the 2 groups during maximal exercise. Using a stepwise regression analysis, the most highly correlated variable to the development of significant ST- segment depression was the $\mathrm{LV}-\mathrm{O}_{2}$ supply-demand ratio during maximal exercise $(\mathrm{r}=0.65, \mathrm{p}<0.001)$. The addition of $L V$ systolic pressure at rest $(\mathrm{r}=0.34, \mathrm{p}=$ $0.16)$ or $L V$ outflow tract gradient at rest $(r=0.18, p=$ 0.47 ) did not contribute to predictive value of the $\mathrm{LV}-\mathrm{O}_{2}$ supply-demand ratio.

Further analysis of the determinants of the $\mathrm{LV}-\mathrm{O}_{2}$ supply-demand ratio using a stepwise regression analysis demonstrated that the variables that were most predictive of the $\mathrm{LV}-\mathrm{O}_{2}$ supply-demand ratio in the 12 patients with treadmill-induced ST-segment depression were LV systolic pressure $(r=0.83, p<0.05)$ and the ratio of the diastolic filling time to the systolic ejection time $(\mathrm{r}=0.89, \mathrm{p}<0.05)$ during maximal supine bicycle exercise. The change in diastolic filling time from rest to maximal supine bicycle exercise decreased slightly more in patients with treadmill-induced ST-segment depression ( $56 \pm 14 \%$ vs $52 \pm 3 \%$ ). The systolic ejection time tended to be longer $(0.18 \pm 0.03$ vs $0.13 \pm 0.02$ second, $p=0.09$ ) during maximal supine bicycle exercise in the 12 children with treadmill-induced ST-segment depression.

No significant differences were seen during supine bicycle exercise in heart rate at rest and during maximal exercise, aortic pressure, cardiac index, stroke index, $\mathrm{O}_{2}$ consumption, pulmonary artery saturation and LV end-diastolic pressure at rest between the 2 groups (Table II). Comparison of supine and treadmill exercise heart rate at rest and during maximal exercise and change in systolic blood pressure during exercise did not reach statistical significance, although a trend did exist to have a lower maximal heart rate during supine exercise (Tables I and II). In 8 of 17 patients, $\mathrm{O}_{2}$ consumption was measured during both treadmill and supine exercise; the maximal $\mathrm{O}_{2}$ consumption was higher 


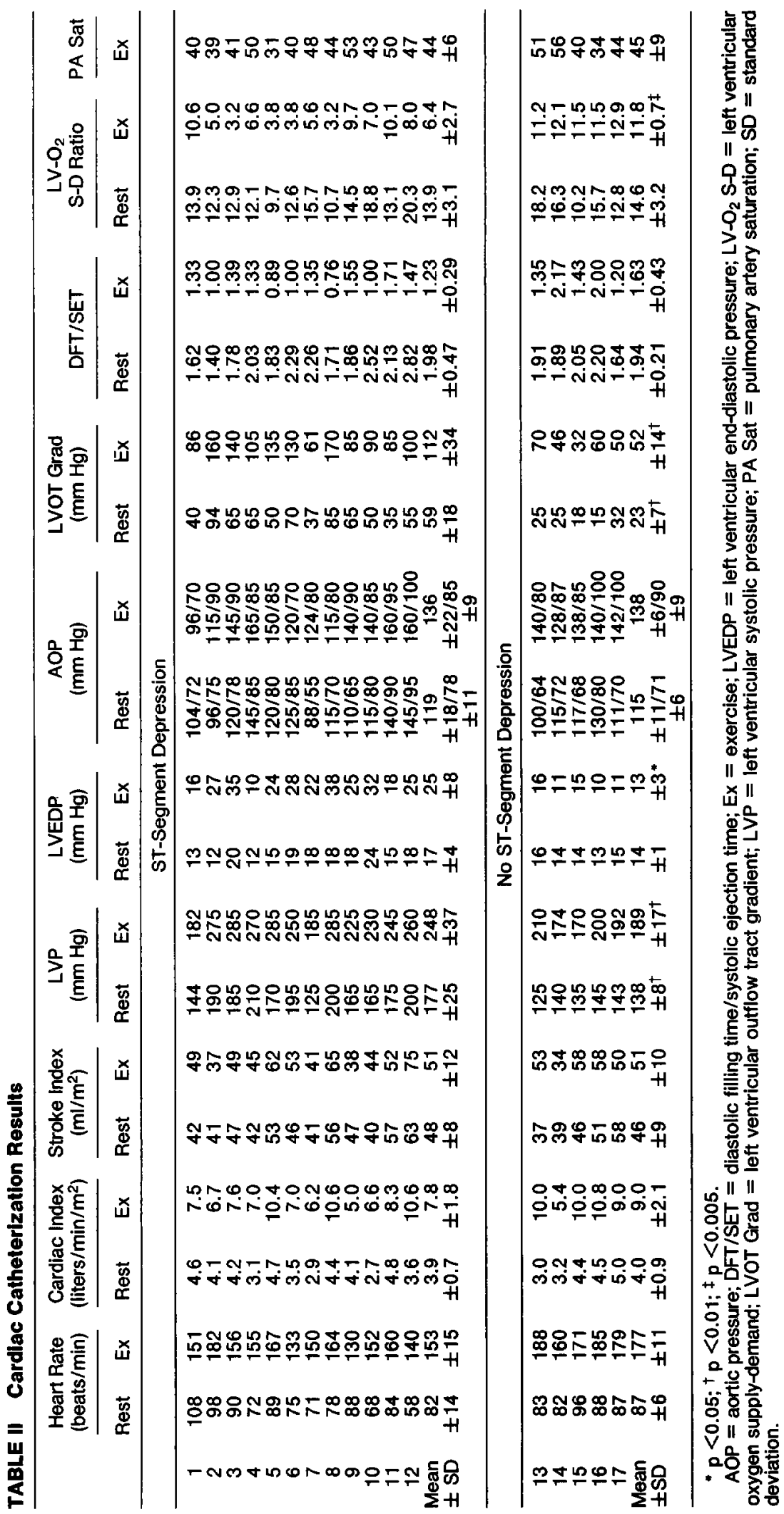


FIGURE 2. Left ventricular (LV) pressure, LV to aortic gradients (LV-AO), and LV end-diastolic pressure (LV-EDP) in patients with and those without ST-segment depression during maximal treadmill exercise both at rest and during maximal exercise (Max Ex). Comparison is made between the ST-segment vs no ST-segment depression groups (" $p$ $\left.<0.05,{ }^{*} p<0.01\right)$. POST-OP = postoperative; SD $=$ standard deviation.

ST-DEPRESSION

$M=12$
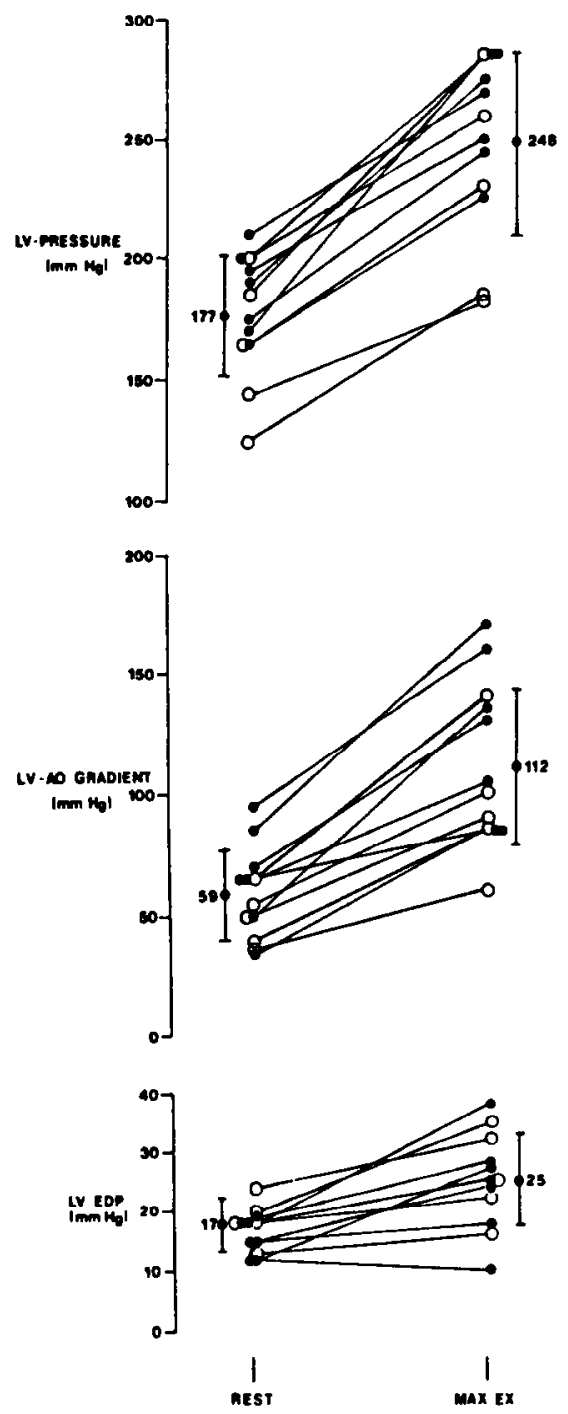

NO ST-DEPRESSION

H.s

OD POST-OR

$\overline{\mathbf{x}} \pm \mathbf{8 0}$
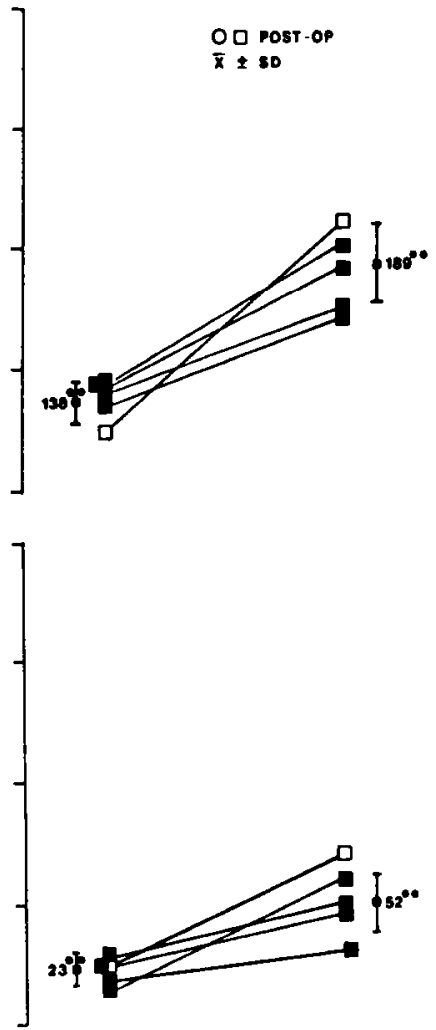

MI

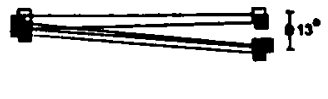

I

1
ST-DEPRESSION

$N=12$
NO ST-DEPRESSION

$M=5$
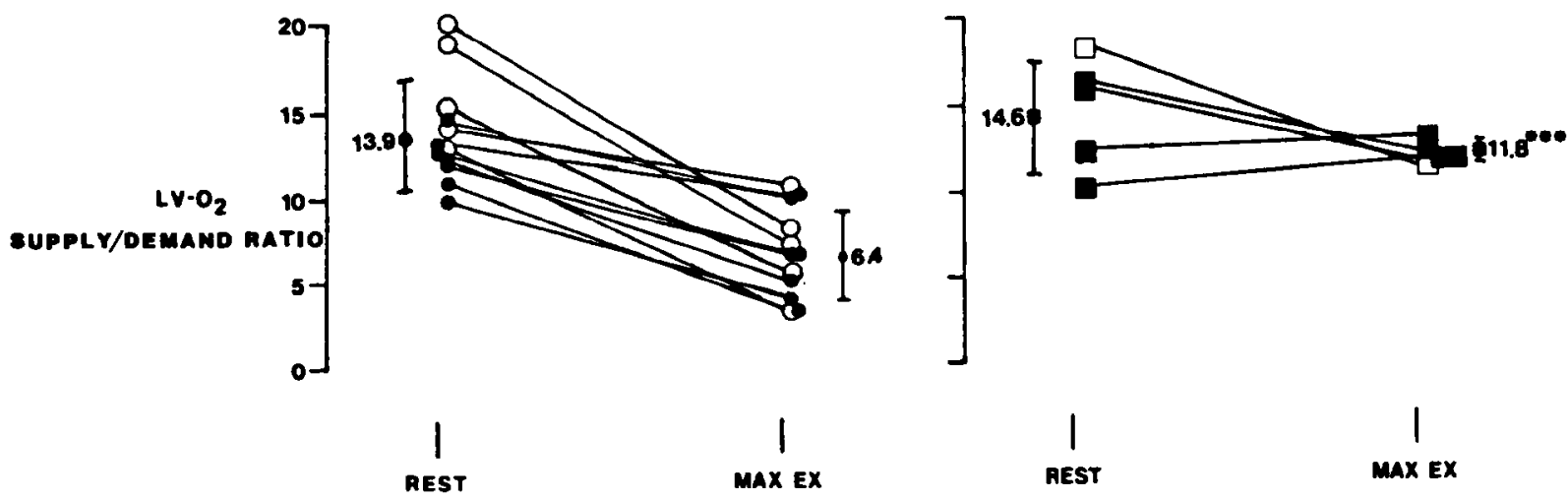

FIGURE 3. Left ventricular- $\mathrm{O}_{2}\left(\mathrm{LV}-\mathrm{O}_{2}\right)$ supply-demand ratio in patients with and those without ST-segment depression both at rest and during maximal exercise (Max Ex). Comparison is made between ST-segment depression group vs no ST-segment depression group. **"p<0.005. 
during treadmill exercise $(40 \pm 9$ vs $28 \pm 6 \mathrm{ml} / \mathrm{kg}, \mathrm{p}$ $<0.05)$. Also, the magnitude of ST-segment depression during maximal supine bicycle exercise in those patients with treadmill-induced ST-segment depression was similar.

\section{Discussion}

The LV outflow tract gradient at rest, presence of symptoms and the development of ST-segment depression during exercise are the 3 major variables considered before recommending an aortic valvotomy in a child with AS. Despite the widespread clinical use of ST-segment depression during exercise as a criterion for operability in the child with AS, a comprehensive concept on its genesis has not been established.

In the present study, the LV pressure and the LV outflow tract gradient at rest and $L V$ outflow tract gradient and LV systolic and end-diastolic pressure during maximal supine bicycle exercise were all helpful in differentiating patients who had ST-segment depression during treadmill exercise, although considerable overlap did exist (Fig. 2). An LV outflow tract gradient at rest of more than $50 \mathrm{~mm} \mathrm{Hg}$ was present in only 7 of 12 patients (58\%) with ST-segment depression during treadmill exercise. This observation is in agreement with the data reported by Chandramouli et $\mathrm{al}^{6}{ }^{6}$ and confirms that resting gradient alone is not the sole determinant of whether ST-segment depression occurs with exercise. An even greater overlap between patients with and without treadmill exercise-induced ST-segment depression was observed for other hemodynamic determinants including: LV systolic pressure, LV end-diastolic pressure, aortic pressure, cardiac index, heart rate or stroke index at rest and during maximal supine exercise. In fact, no single hemodynamic measurement was both $100 \%$ sensitive and specific in predicting the development of significant ST-segment depression during maximal treadmill exercise.

Using a stepwise regression analysis, the $\mathrm{LV}-\mathrm{O}_{2}$ supply-demand ratio during maximal exercise was the most predictive measure of the development of ST depression during treadmill exercise. $\mathrm{LV}-\mathrm{O}_{2}$ supplydemand ratio during maximal supine exercise of more than 11 was both $100 \%$ specific and sensitive in predicting which patient would not have significant STsegment depression during maximal treadmill exercise. In fact, only 2 children (17\%) who did have ST-segment depression had an $\mathrm{LV}-\mathrm{O}_{2}$ supply-demand ratio during maximal exercise of more than 10.0. Our observations are in keeping with those reported by a number of investigators who have demonstrated that patients with AS and ST-segment depression on electrocardiography at rest have an altered $\mathrm{LV}-\mathrm{O}_{2}$ supply-demand ratio. ${ }^{12-16}$ In addition, Rosenthal et $\mathrm{al}^{20}$ demonstrated that isometric handgrip increases the LV work in children; in those with AS, isometric handgrip also frequently depresses the $\mathrm{LV}-\mathrm{O}_{2}$ supply-demand ratio to low levels. ${ }^{20}$

The documented relation between $\mathrm{LV}-\mathrm{O}_{2}$ supplydemand ratio during maximal supine exercise and the development of ST-segment depression during tread- mill exercise is not surprising or unexpected. Others have shown that when the coronary blood vessels are maximally dilated, the $\mathrm{LV}-\mathrm{O}_{2}$ supply-demand ratio accurately estimates the adequacy of $\mathrm{LV}$ subendocardial blood flow. ${ }^{13-16}$ Since the calculation of the $\mathrm{LV}-\mathrm{O}_{2}$ supply-demand ratio includes the measurement of LV systolic and diastolic pressure, aortic pressure and heart rate as expressed by ejection and filling times, these factors are probably the important determinants of coronary blood flow in patients with AS. Using stepwise regression analysis the 2 factors that are most predictive in a child with AS in whom ST-segment depression develops during treadmill exercise are the decrease in the ratio of diastolic filling time to systolic ejection time and increase in LV systolic pressure.

Even though differences exist between supine and upright exercise (including higher LV end-diastolic pressure, end-diastolic volume and stroke index, and lower heart rate and oxygen consumption both at rest and during maximal exercise), we believe the conclusions drawn are valid, since in the 2 groups the magnitude of change in these variables from rest to maximal exercise are similar. ${ }^{21,22}$ In addition, the decrease in pulmonary saturation to $44 \pm 7 \%$ is consistent with the achievement of maximal supine exercise, even though the maximal oxygen consumption during supine exercise was not as large as with treadmill exercise. ${ }^{23}$ Therefore, we speculate that the sequence of events leading to exercise-induced ST-segment depression in children with AS is as follows: Because exercise produces little increase in aortic pressure, a significant increase in LV systolic pressure, the LV myocardial oxygen demand exceeds that provided by coronary perfusion. The decrease in coronary perfusion along with the chronic LV hypertrophy alters the mechanisms responsible for cardiac contraction, resulting in prolonged relaxation and decreased myocardial compliance. The decrease in LV complicance promotes an increase in LV end-diastolic pressure, which inhibits coronary flow from the endocardium and produces a subendocardial zone of ischemia resulting in the characteristic ST-segment depression first recognized in 1918 by Bousfield. ${ }^{24}$ The data presented suggest that hemodynamic data obtained during exercise may aid in the management of patients with AS. In a patient with borderline hemodynamic criteria at rest for valvotomy, the presence of an abnormal $\mathrm{LV}-\mathrm{O}_{2}$ supplydemand ratio is used as an indication for surgery in our institution.

Acknowledgment: We thank John Palmisano and Jean Martin for their technical assistance in performing the treadmill exercise tests and cardiac catheterizations and Lori Bodine for her secretarial assistance in preparing the manuscript.

\section{References}

1. Frledman WF. Indications for and results of surgery in congenital aortic stenosis. Adv Cardiol 1976;17:2-12.

2. Alpert BS, Kartodihardjo W, Harp R, Izukawa T. Exercise blood pressure response: a predictor of severity of aortic stenosis in children. J Pedlatr 1981;98:763-765.

3. Hossack KF, Nelison CH. Exercise testing in congenital aortic stenosis. Aust NZ J Med 1979;9:169-173. 
4. Barton CW, Katz B, Schork MA, Rosenthal A. Value of treadmill exercise test in pre- and postoperative children with valvular aortic stenosis. Clin Cardiol 1983;6:473-477.

5. Wright S, Rosenthal A, Bromberg S, Schork A. R-wave amplitude changes during exercise in adolescents with left ventricular pressure and volume overload. Am J Cardiol 1983;52:841-846.

6. Chandramoull B, Ehmke DA, Lauer RW. Exercise-induced electrocardiographic changes in children with congenital aortic stenosis. J Pediatr 1975:87:725-730

7. James FW, Schwartz DC, Kaplan S, Spllkln SP. Exercise electrocardiogram, blood pressure and working capacity in young patients with valvar or discrete subvalvular aortic stenosis. Am J Cardiol 1982;50:769-775.

8. Bertrand ME, Lablanche JM, Tilmant PY, Thieuleux FP, Delforge MR, Carre AG. Coronary sinus blood flow at rest and during isometric exercise in patients with aortic valve disease: mechanism of angina pectoris in presence tients with aortic valve disease: mechanism of angina pectoris

9. Sarnoft SJ, Braunwald E, Welch GH Jr, Case RB, Stainsby WN, Marcruz R. Hemodynamic determinants of oxygen consumption of the heart with special reference to the tension-time index. Am J Physiol 1958;192. $148-156$.

10. Braunwald E, Sarnoff SJ, Case RB, Stalnsby WN, Welch GH Jr. Hemodynamic determinants of coronary flow: effect of changes in aortic pressure and cardiac output on the relationship between myocardial oxygen conand cardiac output on the relationship between myocardial ox

11. Holfman JIE, Buckberg GD. The myocardial supply:demand ratio-a critical review. Am J Cardiol 1978;41:327-332

12. Vincent WR, Buckberg GD, Hoffman JIE. Left ventricular subendocardial ischemia in severe valvar and supravalvar aortlc stenosis: a common mechanism. Circulation 1974;49:326-333.

13. Brazler J, Cooper $N$, Buckberg $G$. The adequacy of subendocardial oxygen delivery: the interaction of determinants of flow, arterial oxygen content and myocardial oxygen need. Circulation 1974;49:968-977.

14. Buckberg $G$, Eber $L$, Herman $M$, Gorlin $R$. Ischemia in aortic stenosis: hemodynamic prediction. Am J Cardiol 1975;35:778-784.

15. Krovetz LJ, KurlinskI JP. Subendocardial blood flow in children with congenital aortlc stenosis. Clrculation 1976;54:961-965

16. Lewis AB, Heymann MA, Stanger P, Hoffman JIE, Rudolph AM. Evaluation of subendocardial ischemia in valvar aortic stenosis in children. Circulation 1974:49:978-984.

17. Spicer RL, Rocchini AP, Crowley DC, Vasiliades J, Rosenthal A. Hemodynamic effects of verapamil in children and adolescents with hypertrophic cardiomyopathy. Circulation 1983;67:413-420.

18. Buckberg GD, Fixler DE, Archie JP, Hoffman JIE. Experimental subendocardial ischemia in dogs with normal coronary arteries. Circ Res 1972;30:67-81.

19. Rocchinl AP. Hemodynamic abnormalities in response to supine exercise in patients after operative correction of tetrad of Fallot after early childhood. Am J Cardiol 1981;48:325-330.

20. Rosenthal A, Freed MD, Keane JF. Isometric exercise in adolescents with congenital aortic stenosis (abstr). Circulation 1976;54:suppl II:II-48.

21. Thadaniv, Parker Jo. Hemodynamics at rest and during supine and sitting bicycle exercise in normal subjects. Am J Cardiol 1978;41:52-59.

22. Poliner LR, Dehmer GJ, Lewis SE, Parkey RW, Blomqvist G, Willerson JT. Left ventricular performance in normal subjects: a comparison of the response to exercise in the upright and supine positions. Circulation 1980;62:528-534.

23. Lock JE, Elnzig S, Moller JH. Hemodynamic responses to exercise in normal children. Am J Cardiol 1978;41:1278-1284.

24. Bousfield G. Angina pectoris: changes in electrocardiogram during paroxysm. Lancent 1918;2:457-458. 